\title{
Experiência multidisciplinar exitosa em instituição de longa permanência para idosos durante a pandemia da COVID-19
}

Successful multidisciplinary experience in a long stay institution for the elderly during the COVID19 pandemic

Experiencia multidisciplinar exitosa en una institución de larga estancia para ancianos durante la pandemia COVID-19

Bianca Cristina Marques Gindre laubert

ORCID: https://orcid.org/0000-0002-8901-5342 Universidade Federal do Estado do Rio de Janeiro, Brasil E-mail: biancagindre@yahoo.com.br

Beatriz Gerbassi Costa Aguiar

ORCID: https://orcid.org/0000-0001-6815-4354 Universidade Federal do Estado do Rio de Janeiro, Brasil E-mail: nildo.ag @terra.com.br

Maithê de Carvalho e Lemos Goulart ORCID: https://orcid.org/0000-0003-2764-5290

Universidade Federal Fluminense, Brasil, Brasil E-mail: maithegoulart@gmail.com

Vivian Farias da Fonseca

ORCID: https://orcid.org/0000-0002-1405-1058 Aeronáutica, Brasil

E-mail: vivianffonseca24@gmail.com

Patrícia Aparecida Tavares Mendes

ORCID: https://orcid.org/0000-0003-2224-1932 Universidade Federal do Estado do Rio de Janeiro, Brasil E-mail: patricia.patm@yahoo.com.br

Daniela de Oliveira Matias celular ORCID: https://orcid.org/0000-0003-4177-6799 Universidade Federal do Estado do Rio de Janeiro, Brasil E-mail: danielamatiasenf@hotmail.com

Tamires Zeba Guimaraes

ORCID: https://orcid.org/0000-0001-5832-7696 Universidade Federal do Estado do Rio de Janeiro, Brasil E-mail: tamires.zeba@edu.unirio.br

\begin{abstract}
Resumo
Objetivo: relatar a experiência e os desafios do serviço multidisciplinar em uma instituição de longa permanência para idosos durante a pandemia da COVID-19 no Brasil. Método: Trata-se de estudo descritivo, do tipo relato de experiência sobre a experiência e os desafios do serviço multidisciplinar em uma ILPI durante a pandemia da COVID19, no Brasil. Resultados: O acompanhamento do serviço multidisciplinar ocorreu entre fevereiro de 2020 e fevereiro de 2021. Durante esse período houve a reorganização do plano de cuidados assistenciais, com a implementação de ações para promoção e proteção a saúde dos idosos, além da maior adesão aos processos focados no combate a pandemia como o isolamento dos casos suspeitos, restrição das visitas, coleta de exame para monitoramento dos casos suspeitos e confirmados de COVID-19, entre outros. A exposição dos medos e angústias dos idosos e de toda a equipe multidisciplinar foi evidenciada, como a consequência da nova organização do serviço. Conclusão: a pandemia traz desafios na assistência de enfermagem ao idoso institucionalizado, requerendo cooperação e mudança abrupta de conduta da equipe multidisciplinar.
\end{abstract}

Palavras-chave: Assistência domiciliar; COVID-19; Instituição de longa permanência para idosos; Promoção da saúde; Prevenção de doenças.

\section{Abstract}

Objective: to report the experience and challenges of the multidisciplinary service in a long-stay institution for the elderly during the COVID-19 pandemic in Brazil. Method: This is a descriptive study, of the type of experience report, on the experience and challenges of multidisciplinary service in an LSIE during the COVID-19 pandemic in Brazil. Results: The monitoring of the multidisciplinary service took place between February 2020 and February 
2021. During this period there was a reorganization of the care plan, with the implementation of actions to promote and protect the health of the elderly, in addition to greater adherence to processes focused on combating the pandemic, such as isolating suspected cases, restricting visits, collecting exams for monitoring suspected and confirmed cases of COVID-19, between others. The exposure of fears and anxieties of the elderly and the entire multidisciplinary team was evidenced as a consequence of the new organization of the service. Conclusion: the pandemic brings challenges in nursing care for institutionalized elderly, requiring cooperation and an abrupt change in the conduct of the multidisciplinary team.

Keywords: Home nursing; COVID-19; Homes for the aged; Health promotion; Disease prevention.

\section{Resumen}

Objetivo: reportar la experiencia y desafíos del servicio multidisciplinario en una institución de larga estancia para ancianos durante la pandemia COVID-19 en Brasil. Método: Se trata de un estudio descriptivo, del tipo informe de experiencia, sobre la experiencia y desafíos del servicio multidisciplinario en una LSIE durante la pandemia de COVID-19 en Brasil. Resultados: El seguimiento del servicio multidisciplinario se llevó a cabo entre febrero de 2020 y febrero de 2021. Durante este período se realizó una reorganización del plan de atención, con la implementación de acciones para promover y proteger la salud de las personas mayores, además de una mayor adherencia a los procesos enfocados al combate de la pandemia, tales como aislamiento de casos sospechosos, restricción de visitas, recolección de exámenes para el seguimiento de casos sospechosos y confirmados de COVID-19, entre otros. La exposición de miedos y ansiedades de los ancianos y de todo el equipo multidisciplinario se evidenció como consecuencia de la nueva organización del servicio. Conclusión: la pandemia trae desafíos en la atención de enfermería al anciano institucionalizado, requiriendo cooperación y un cambio brusco en la conducta del equipo multidisciplinario.

Palabras clave: Atención domiciliaria de salud; COVID-19; Hogares para ancianos; Promoción de la salud; Prevención de enfermedades.

\section{Introdução}

As Instituição de Longa Permanência para Idosos, ILPI, termo adaptado do usado pela Organização Mundial de Saúde, Long-Term Care Institution e conforme definição da Agência Nacional de Vigilância sanitária (Anvisa) são instituições governamentais ou não governamentais, que tem caráter domiciliar coletivo de pessoas com idade igual ou superior a 60 anos, com ou sem suporte familiar que em condição de liberdade e dignidade e cidadania buscam dar suporte de alimentação, higiene e condições de moradia ( Meleiro, 2016).

Em 2019, A Organização Mundial de Saúde (OMS) foi informada, sobre diversos casos de pneumonia na cidade de Wuhan, China (OPAS, 2020). Tal doença era causada por um novo tipo de coronavírus, que ainda não havia sido relatado em humanos, denominado Severe Acute Respiratory Syndrome Coronavirus-2 (SARS-CoV-2). A infecção pelo novo coronavírus, em humanos, causa a doença chamada de Coronavirus Disease-19 (COVID-19) (Zhu N et al, 2020). Esta síndrome respiratória é potencialmente grave, de elevada transmissibilidade e de distribuição global que vem causando preocupação em todo o mundo. A parcela da população que apresenta maior risco, maior vulnerabilidade de desenvolver a forma mais grave da doença, levando ao óbito são os idosos.

No dia 26 de fevereiro de 2020, o Ministério da Saúde (MS) do Brasil confirmou o primeiro caso de COVID-19 em um idoso de 61 anos que retornava da Lombardia, Itália, e que apresentou febre com sintomas respiratórios, com confirmação laboratorial da infecção pelo SARS-CoV-2. Ressalta-se que o índice de mortalidade aumenta com a idade nos seguintes percentis: 3,6 \% na população entre 60-69 anos, 8\% entre indivíduos de 70-79 anos e 14,8 \% nos maiores de 80 anos. Segundo a Sociedade Brasileira de Geriatria e Gerontologia (2020) pessoas residentes em Instituições de Longa Permanência para Idosos (ILPI) são mais vulneráveis à infecção pelo SARS-CoV-2, por serem mais fragilizadas e apresentarem comorbidades e idade avançada, além de manterem contato próximo com cuidadores e profissionais de saúde, que podem atuar como fontes de transmissão da COVID-19 (Zhou F et al, 2020).

Conforme Zhou F, et al (2020) a vulnerabilidade dos idosos, residentes das ILPI à surtos de doenças respiratórias, como influenza, resfriado comum e o novo coronavírus é notória. Os idosos institucionalizados estão sujeitos a desenvolver a COVID-19, em especial, aqueles com idade maior que 80 anos e comorbidades, como diabetes, hipertensão e doenças 
cardiovasculares, que apresentam maior risco para desfechos desfavoráveis (Associação Brasileira de Fisioterapia em Gerontologia, 2020).

Em uma ILPI americana, 167 casos confirmados de COVID-19 distribuíram-se entre 101 residentes, 50 profissionais de saúde e 16 visitantes relacionados com a instituição. Nesse cenário, 34 dos residentes infectados evoluíram para óbito, caracterizando o efeito devastador da doença.7 Esta realidade despertou o alerta dos gestores que atuam em ILPI, cabendo à eles a tomada de decisões difíceis sobre como proteger a população de residentes da exposição ao novo coronavírus, enquanto atentam para os riscos potenciais à saúde causados pelo isolamento adicional de uma população já negligenciada e vulnerável.

Neste interim, este estudo tem como objetivo relatar a experiência e os desafios do serviço multidisciplinar de uma ILPI no decorrer da pandemia da COVID-19 no Brasil.

\section{Metodologia}

Trata-se de estudo descritivo, do tipo relato de experiência sobre a experiência e os desafios do serviço multidisciplinar em uma ILPI durante a pandemia da COVID-19 no Brasil, no período entre fevereiro de 2020 e fevereiro de 2021.

A ILPI que compôs o cenário deste relato, está localizada no município do Rio de Janeiro e possui 120 leitos, onde atualmente 86 estão em pleno funcionamento. Disponibiliza atendimentos de geriatria e gerontologia a idosos, que são internados no regime de residência e recebem assistência médica e de enfermagem $24 \mathrm{~h}$, além do atendimento de outras especialidades como psicologia, fisioterapia, musicoterapia, educação física, terapia ocupacional, acupuntura, fonoaudiologia, serviço social e toda uma rede de estrutura de apoio organizada para o gerenciamento do cuidado dos idosos residentes.

A referida instituição contava com um total de 95 idosos residentes, contudo, em função do anúncio das medidas de distanciamento social, cinco optaram por retornar às suas residências externas ou às casas de familiares. A equipe multidisciplinar é composta por duas enfermeiros, 40 técnicos de enfermagem, seis médicos geriatras, cinco fisioterapeutas, dois fonoaudiólogos, três assistentes sociais, quatro dentistas, duas terapeutas ocupacionais, duas nutricionistas, dois musicoterapeutas e dois psicólogos.

Para a descrição do relato foram considerados cinco momentos, com base no autor Oscar (2006), a saber: 1) O ponto de partida; 2) As perguntas iniciais; 3) Recuperação do processo vivido; 4) A reflexão de fundo e 5) Os pontos de chegada. No primeiro momento considerou-se a participação das autoras enquanto membros da equipe do serviço multidisciplinar e seu papel ativo nas tomadas de decisões gerenciais. Todas as atividades foram registradas em diário de campo, além dos protocolos elaborados durante o período, favorecendo o resgate à memória dos eventos ocorridos em ordem cronológica.

No segundo momento, elencou-se a pergunta inicial: Como podemos orientar e reorganizar o cuidado multidisciplinar em uma ILPI, a partir da experiência relatada durante a pandemia de COVID-19? Por meio desta pergunta, estabeleceu-se como o objeto de relato as experiências e os desafios enfrentados pela equipe multidisciplinar frente a reorganização do cuidado aos idosos residentes em uma Instituição de Longa Permanência, durante a pandemia. Considerou-se como eixo de sistematização a contribuição para a reorganização do cuidado nas ILPI: experiências, desafios enfrentados e novas propostas frente à pandemia de COVID-19.

Os três momentos restantes, serão descritos nas seções seguintes deste relato de experiência, considerando o terceiro momento como a reconstrução dos fatos e a ordenação das informações, no quarto momento a análise, síntese e interpretação crítica do processo de reorganização do cuidado e, no quinto e último momento, a formulação das conclusões e o comunicado de aprendizagem.

Dispensou-se apreciação deste relato de experiência em Comitê de Ética em Pesquisas, uma vez que nenhum idoso ou profissional foi abordado para coleta de dados. 


\section{Resultados}

No dia 13 de março de 2020, após anúncio da ocorrência de transmissão comunitária da COVID-19 no estado do Rio de Janeiro, a equipe multidisciplinar reuniu-se para discutir um plano de ação com o propósito de diminuir a exposição dos idosos residentes à infecção pelo novo coronavírus. Imediatamente foram adotadas medidas preventivas, como a implementação de barreiras físicas na entrada, a suspensão das atividades do Centro de Convivência, das atividades em grupo, dos atendimentos eletivos de odontologia e da saída dos idosos, bem como a proibição de visitas aos residentes.

Com base nas normas técnicas, resoluções e orientações mais atualizadas sobre a COVID-19, de diversos órgãos brasileiros e internacionais (Ministério da saúde, 2020), a equipe multidisciplinar reorganizou o plano de cuidados dos idosos residentes e implementou novas medidas gerenciais (Quadro 1).

Quadro 1 - Medidas emergenciais utilizadas na ILPI para o enfrentamento da COVID-19 no Brasil, Rio de Janeiro, RJ, 2021.

\begin{tabular}{|c|c|}
\hline Tipo de medida & Descrição da medida emergencial adotada \\
\hline \multirow{6}{*}{ Gerencial } & Suspensão de visitas aos idosos residentes \\
\hline & Suspensão de atividades coletivas no âmbito da ILPI \\
\hline & Suspensão de admissões de idosos para residência \\
\hline & Restrição da circulação de idosos pelas dependências da ILPI \\
\hline & Suspensão das refeições comunitárias no refeitório \\
\hline & Entrega de refeições aos idosos residentes em seus quartos \\
\hline \multirow[t]{3}{*}{$\begin{array}{l}\text { Controle de casos } \\
\text { suspeitos e confirmados } \\
\text { de COVID-19 }\end{array}$} & $\begin{array}{l}\text { Coleta de RT-PCR de todos os idoso residentes, cuidadores, equipe multidisciplinar e de } \\
\text { apoio da ILPI para rastreamento no início da pandemia e em janeiro de } 2021 \text {, após as festas } \\
\text { de final de ano, já que alguns idosos foram passar as comemorações de final de ano com seus } \\
\text { familiares, Ao retornar para a ILPI depois das festas os idosos ficaram } 14 \text { dias isolados como } \\
\text { prevenção e avaliação de sinais e sintomas diminuindo o risco de contaminação da ILPI } \\
\text { considerando que os idosos moram em quartos individuais. Os idosos que permaneceram na } \\
\text { ILPI receberam visitas, mantendo o distanciamento, uso de máscaras e álcool em gel. }\end{array}$ \\
\hline & Monitoramento de casos suspeitos e confirmados \\
\hline & Isolamento dos casos confirmados. Primeira testagem tivemos: 11 resultados positivam \\
\hline \multirow{3}{*}{$\begin{array}{l}\text { Direcionada à equipe } \\
\text { multidisciplinar }\end{array}$} & $\begin{array}{l}\text { Capacitação para o enfrentamento da doença (que incluiu informações pertinentes ao } \\
\text { reconhecimento de casos suspeitos, cuidados no uso de Equipamentos de Proteção Individual } \\
\text { (EPI) e atualização terapêtica) }\end{array}$ \\
\hline & $\begin{array}{l}\text { Instalação de bancadas de apoio para paramentação do lado de fora dos quartos dos idosos } \\
\text { residentes isolados por suspeita ou confirmação de COVID-19 }\end{array}$ \\
\hline & Gestão de distribuição de EPI pela farmácia da instituição \\
\hline \multirow{2}{*}{ Rotinas e Fluxos } & $\begin{array}{l}\text { Estabelecimento de fluxo de entrada e saída da ILPI, com realização de triagem de casos } \\
\text { suspeitos de COVID-19 }\end{array}$ \\
\hline & $\begin{array}{l}\text { Construção e implementação dos principais processos relacionados ao enfrentamento da } \\
\text { doença, por meio de Protocolos de Operação Padrão (POP). }\end{array}$ \\
\hline \multirow{2}{*}{ Suporte psicoemocional } & Orientação e suporte aos familiares e cuidadores dos idosos residentes \\
\hline & Atendimento regular com psicóloga da equipe multidisciplinar \\
\hline
\end{tabular}

Fonte: Autores.

Vale ressaltar também a elaboração e implementação de cinco novos Procedimentos Operacionais Padrão (POP), que versavam sobre: transporte de idosos residentes com COVID-19 em ambulância para atendimento emergencial em hospitais, reforço das medidas de limpeza e desinfecção da instituição, fluxo de atendimento aos idosos residentes com suspeita ou confirmação de COVID-19, gerenciamento dos resíduos de serviços de saúde durante a pandemia e preparo do corpo pósóbito de idosos, residente com COVID-19.

A partir da reunião da definição das medidas emergenciais, em 13 março de 2020, a equipe passou também a registrar todos os casos de infecção, cura e óbito ocorridos na ILPI. Para considerar um caso como confirmado de infecção pelo novo coronavírus, o critério selecionado foi detecção por RT-PCR em amostra de swab nasal. Adotou-se como critério de cura a negativação do RT-PCR em amostra semelhante, colhida a partir de 14 dias após o primeiro sintoma da doença. Durante o período estabelecido para este relato, foram registrados 28 casos de COVID-19, com 5 óbitos confirmados pela doença e taxa 
de letalidade de 0,18 na ILPI (Figura 1).

Figura 1 - Distribuição temporal dos casos, óbitos e cura da COVID-19 em idosos residentes na ILPI, Rio de Janeiro, RJ, 2021.

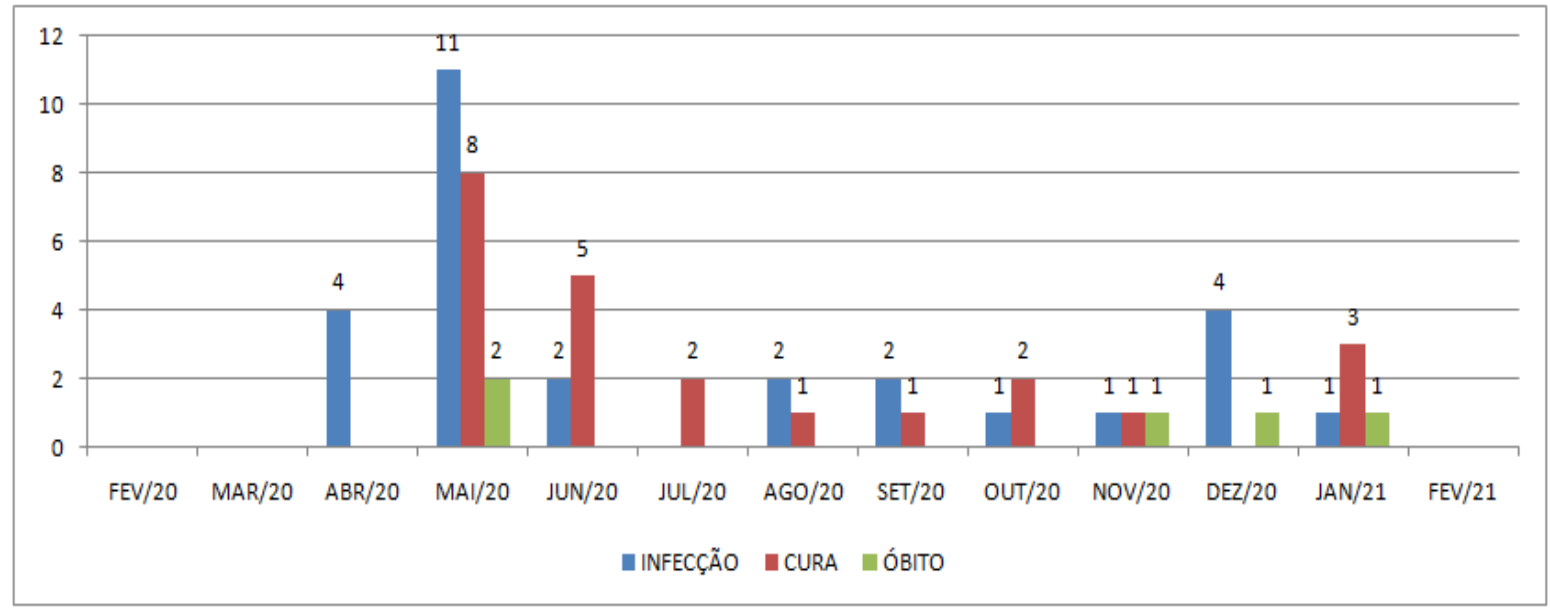

Fonte: Dados do estudo (2021).

Desde marco de 2020 até janeiro de 2021, foi mantida a conduta de vigilância e controle rigoroso das medidas adotadas em reunião, foi possível assim, controlar o surto de COVID-19 dentro da ILPI, demonstrada pela queda da incidência da doença. Em dezembro de 2020, após a autorização de saída alguns idosos (05) optaram para passar as festas de final de ano na residência de suas famílias. Ao retornar ficaram isolados por 14 dias para monitorar sinais e sintomas e prevenção de contaminação da ILPI. Os idosos que ficaram na ILPI e receberam visitas cumpriram os protocolos de distanciamento: sem contato, 2 metros de distância, uso de máscara e álcool em gel. As visitas eram separadas por corredores, um corredor por dia da semana. Assim era mantido o controle de quantidade de pessoas circulando. O local era um grande salão onde o acesso das visitas era pela área externa e os residentes eram pela área interna. As visitas aconteciam supervisionadas por profissionais de saúde, houve a preocupação com o aumento dos casos novamente e, a partir disto, surgiu a necessidade de nova testagem dos idosos residentes da ILPI.

Em janeiro de 2021, tão logo disponibilizada vacina específica contra a COVID-19, a ILPI iniciou um amplo movimento de vacinação de idosos residentes, cuidadores e equipe multidisciplinar, em conformidade com as determinações do Ministério da Saúde (MS). A intenção foi vacinar, com a maior velocidade possível, o número máximo de pessoas relacionadas à ILPI, a fim de conferir a necessária proteção aos idosos residentes contra as formas mais graves da doença. As vacinas utilizadas foram CoronaVac e AstraZeneca, fornecidas pela Secretaria Municipal de Saúde do Rio de Janeiro. 
Figura 2 - Cobertura Vacinal dos trabalhadores, idosos residentes e cuidadores da ILPI, Rio de Janeiro, RJ, 2021.

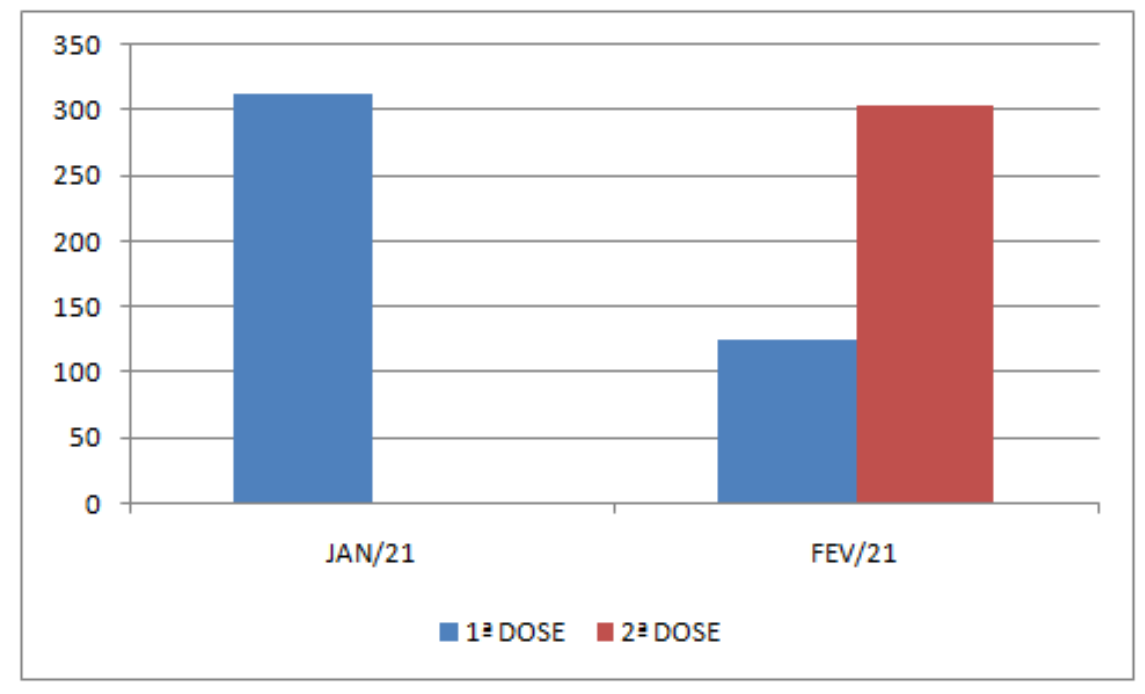

Fonte: Dados do estudo (2021).

Até o final de fevereiro de 2021, 441 (97,3\%) de todos os indivíduos que circulam na ILPI haviam sido vacinados com pelo menos a primeira dose da vacina. Vale destacar que destes, a cobertura vacinal dos 86 idosos residentes foi de 100,0\% e 173 (98,9\%) de seus cuidadores também foram vacinados. Além disto, 191 (95,5\%) dos trabalhadores da ILPI incluindo o serviço multidisciplinar, a equipe da faxina, administrativos entre outros, também foram imunizados com a vacina contra a COVID-19.

\section{Discussão}

Segundo dados do Ministério da Saúde (2020), o maior número de óbitos da COVID-19, ocorreu na população idosa. Pessoas a partir de 60 anos apresentam mais riscos de óbitos do que quando comparado às faixas etárias mais jovens. $\mathrm{O}$ rastreamento desenvolvido por meio de protocolos, auxiliam a equipe gestora e de cuidadores na elaboração de estratégias de enfrentamento, as quais visam a identificação precoce de indivíduos infectados para a interrupção da transmissão.

Este estudo descreveu a experiência do serviço multidisciplinar em uma ILPI, no decorrer da pandemia e relatou os principais desafios apresentados neste contexto, especialmente no controle de algumas particularidades que aumentam a chance de transmissão do novo coronavírus em ILPIs e merecem destaque.

Uma das melhores formas, adotadas que preservem a vida das pessoas idosas residentes nessas instituições, são as boas práticas, como identificação precoce de indivíduos infectados para que desta forma interrompam o ciclo da transmissão. Essas medidas podem ser adotadas a partir de protocolos que identifiquem práticas a serem adotadas na prevenção e controle da doença.

Em consonância a Resolução RDC n 283, de 26 de setembro de 2005 da ANVISA, tais ambientes, é comum e desejável a realização de refeições e atividades sociais em grupo, o que reforça o caráter de comunidade e pode beneficiar aspectos emocionais dos idosos residentes.

Diante do cenário de transmissão da COVID-19 e a repercussão na saúde do idosos, foi necessário a confecção do documento de Orientações de prevenção e controle de infecção para instituições de longa permanência no contexto da COVID19, em janeiro de 2021 pelas Organizações pan-americanas de saúde- OPAS, devido a grande preocupação com a vulnerabilidade dos idosos, neste documento foi observado a necessidade de medidas mais rígidas como um afastamento social e a suspensão de algumas atividades que eram realizadas em grupo e com a restrição temporária da circulação dos idosos 
residentes pela ILPI, essas recomendações foram implementadas na instituição. 14 Para minimizar os danos do isolamento foram desenvolvidas atividades nos quartos individualmente, shows vistos das janelas dos quartos nas datas comemorativas, missas em locais abertos e com redução de pessoas, seções de terapias por telefone, e vale ressaltar o acolhimento do serviço multidisciplinar em todo o processo da pandemia.

Ademais, outra questão que merece destaque é o fato de que, em função do maior grau de dependência, idosos institucionalizados com frequência requerem cuidadores para auxílio na prática de atividades cotidianas. No contexto da pandemia, a convivência dos idosos com cuidadores, que circulam diariamente pela cidade em coletivos e atuam como potenciais carreadores do vírus para o interior das instituições torna-se uma questão das mais delicadas, uma vez que, apesar do risco, uma parcela expressiva dos idosos não podem abdicar da presença constante dos cuidadores. Os cuidadores apresentam um importante papel na prática da assistência ao idoso institucionalizado, ele é responsável por oferecer cuidado para suprir a incapacidade do idoso, que pode ser temporária ou definitiva (World Health Organization, 2020).

Para Caldas (2020) o cuidador é essencial na melhoria da qualidade de vida do idoso, auxiliando-os na supervisão das atividades e até mesmo na administração de medicamentos, alimentação, higiene, entre outras.

Um agravante é o fato de que, por necessidade financeira, cuidadores com sintomas de COVID-19 podem resistir às orientações de afastamento, ou mesmo dissimular tais sintomas, por receio de serem penalizados pelo seu contratante. Em consonância, a equipe multiprofissional desenvolveu estratégicas para a educação em saúde de cuidadores para a lavagem das mãos, modo de transmissão da doença, sinais e sintomas mais recorrentes da COVID-19. O intuito foi a disseminação de informações de qualidade, através de aulas práticas, reuniões on-line e de fluxograma detalho das atividades que foram disponibilizados para cada quarto dos idosos.

A Frente Nacional de Fortalecimento à Instituição de Longa Permanência para Idoso (2020), enfatiza educação permanente dos profissionais de enfermagem que atuam em ILPI devem ser implementadas, através da disseminação do conhecimento e adoção de medidas preventivas. Assim, faz-se necessária a capacitação de cuidadores e equipe da ILPI para uma intervenção prévia com intuito de proteção dos residentes.

Um ponto adicional é a percepção de que alguns idosos não conseguem compreender ou colocar em prática as orientações de higiene recomendadas, seja por limitações cognitivas. Pessoas com demência oferecem um desafio ainda mais instigante, uma vez que podem não aceitar o uso de máscaras para proteção. Para tais residentes, o isolamento nos quartos foi a medida adotada na ILPI, porém tal restrição gerou tensões e a percepção da equipe multidisciplinar, de que a restrição de circulação acarretou prejuízos funcionais e de humor nestes idosos.

Verificou-se dificuldade crescente na prestação de cuidados à população idosa vulnerável pelas restrições impostas para impedir a propagação da COVID-19, que impactam sobretudo os pacientes que já apresentam limitações funcionais (Brasil, 2021). Na ILPI, cenário deste relato, a fim de reduzir os danos funcionais e promover o bem-estar emocional, assim que os residentes foram considerados imunizados, retomaram-se os atendimentos individuais pelos profissionais de reabilitação, com ênfase em fisioterapia e fonoaudiologia. Ademais, caminhadas individuais ou, no máximo, na companhia do cuidador, foram estimuladas nas áreas externas, com a intenção de reduzir a sensação de confinamento. Medidas de distanciamento e o uso da máscara fizeram parte das recomendações habituais, reforçadas com residentes e cuidadores pela equipe, tanto por meio de repetidas orientações verbais como por comunicações por escrito.

O efeito da COVID-19 em outras ILPIs foi devastador, com elevados índices de mortalidade entre os idosos residentes. No entanto, a pronta intervenção da equipe multidisciplinar, com base na adoção de protocolos nacionais e internacionais e constante atualização, geraram ótimos resultados.

Este estudo apresentou como a intervenção preventiva utilizada como estratégia do serviço multidisciplinar, em pandemia viral de alta transmissibilidade e com elevada mortalidade em idosos institucionalizados, pode contribuir para 
mitigar os danos à saúde dos idosos em uma ILPI.

\section{Conclusão}

Neste cenário de pandemia, e diante do crescimento contínuo da população idosa brasileira, as ILPIs vem como uma forte alternativa de proporcionar a pessoa idosa os cuidados necessários para o processo de envelhecimento. A vulnerabilidade dos idosos é um desafio para o serviço multidisciplinar e a busca por medidas e estratégias frente a COVID-19 para o melhor funcionamento e qualidade da assistência prestada foi o que motivou a desenvolver um programa de prevenção que precisou do engajamento e dedicação de toda a equipe.

Este relato de experiência evidenciou que as medidas imediatas de prevenção e contenção do surto de COVID-19, adotadas na ILPI, fez com que o impacto da pandemia fosse minimizado e a letalidade pela doença não atingisse em números alarmantes os idosos residentes, apesar das suas fragilidades e comorbidades pré-existentes. Vale ressaltar ainda, que a cobertura vacinal de $97,3 \%$ na ILPI pode corroborar significativamente para que tais dados se mantenham ou reduzam ainda mais, desde que mantidas as estratégias de prevenção e contenção do surto já implementadas.

Os resultados indicam que medidas gerenciais preventivas em ILPIs, elaboradas pelo serviço multidisciplinar com múltiplos olhares para a integralidade das ações, e quando adotadas rapidamente no começo de epidemias, pode surtir um efeito positivo na proteção a saúde e preservação da vida dos idosos residentes. Este relato possui limitação no que se refere aos dados no âmbito de uma ILPI, o que impossibilita a generalização dos achados, contudo sugere-se novos estudos que congreguem medidas utilizadas e o impacto das mesmas nos casos de COVID-19 em idosos residentes em ILPIs de diversos contextos brasileiros.

\section{Referências}

Agência Nacional de Vigilância Sanitária. (2020). Nota Técnica GVIMS/ANVISA N 05/2020 - Orientações Para a Prevenção e o Controle de Infecções Pelo Novo Coronavírus em Instituições de Longa Permanência Para Idosos (ILPI). https://www.gov.br/anvisa/ptbr/centraisdeconteudo/publicacoes/servicosdesaude/notas-tecnicas/nota-tecnica-no-05-2020-gvims-ggtes-anvisa-orientacoes-para-a-prevencao-e-o-controlede-infeccoes-pelo-novo-coronavirus-em-instituicoes-de-longa-permanencia-para-idosos-ilpi.pdf/view

Agência Nacional de Vigilância Sanitária. (2005). RDC n ${ }^{\circ}$ 283.Regulamento técnico para o funcionamento das instituições de longa permanência para idosos. https://bvsms.saude.gov.br/bvs/saudelegis/anvisa/2005/res0283_26_09_2005.html\#: :text=4.1\%20\%2D\%20A\%20Institui\%C3\%A7\%C3\%A3o\%20de\%20Lo nga,e\%20individuais)\%20de\%20seus\%20residentes

Armitage, R., \& Nellums, L. B. (2020). COVID-19 and the consequences of isolating the elderly. The Lancet Public Health, 5(5), 235296. https://doi.org/10.1016/S2468-2667(20)30061-X

Associação Brasileira de Fisioterapia em Gerontologia. (2020). Assistência fisioterapêutica à pessoa idosa em tempos da COVID-19. https://abrafige.com.br/nota-da-abrafige-assistencia-fisioterapeutica-a-pessoa-idosa-em-tempos-de-covid-19/

Brasil. (2021). Ministério da Saúde. Secretaria de Vigilância em Saúde. Boletim Epidemiológico Especial 89 - Doença pelo Novo Coronavírus - COVID-19. https://www.gov.br/saude/pt-br/centrais-de-conteudo/publicacoes/boletins/boletins-epidemiologicos/covid-

19/2021/boletim_epidemiologico_covid_89_23nov21_fig37nv.pdf

Boldrini, P., Bernetti, A., \& Fiore P. (2020). Impact of COVID-19 outbreak on rehabilitation services and Physical and Rehabilitation Medicine (PRM) physicians' activities in Italy. An official document of the Italian PRM Society (SIMFER). European Journal of Physical and Rehabilitation Medicine, 56(3), 316-318. https://doi.org/10.23736/S1973-9087.20.06256-5

Brasil. (2020). Ministério da Saúde. Nota Técnica $\quad N^{o}$ 4/2020-SAPS/MS. https://www.conasems.org.br/wpcontent/uploads/2020/04/Nota_0014432584_Nota_Tecnica_n_4_2020_SAPS_MS.pdf

BRASIL. (2021). República Federativa do Brasil. Câmara dos Deputados. Projeto de Lei $\mathrm{n}^{\circ} 4702$, de 09 de novembro de 2012. https://www.camara.leg.br/proposicoesWeb/prop_mostrarintegra;jsessionid=B88735A954931A30AB434DB0FE42CDCE.proposicoesWebExterno1?codteor= $1828821 \&$ filename $=$ Avulso+-PL+4702/2012

Caldas, C. P. (2020). O idoso em processo de demência: o impacto na família. Rio de Janeiro: Editora Fiocruz. https://books.scielo.org/id/d2frp/pdf/minayo9788575413043-05.pdf

Sociedade Brasileira de Geriatria e Gerontologia. (2020). Frente Nacional de Fortalecimento à Instituição de Longa Permanência para Idoso. Boas práticas para as Instituições de Longa Permanência para Idosos no enfrentamento da pandemia de Covid-19: estratégias e protocolos. https://sbgg.org.br/wpcontent/uploads/2020/06/FN-BOAS-PRA\%CC\%81TICAS-FICHA-C.pdf 
Research, Society and Development, v. 11, n. 2, e16211225493, 2022

(CC BY 4.0) | ISSN 2525-3409 | DOI: http://dx.doi.org/10.33448/rsd-v11i2.25493

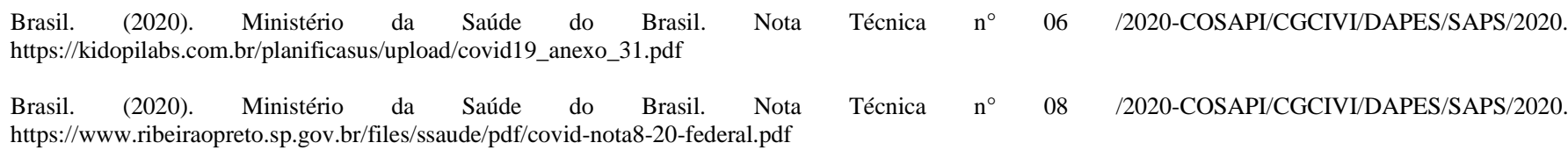

Meleiro, M. R. (2016). As Instituições de Longa Permanência para Idosos sob a perspectiva de um novo modelo. Revista Jurídica ESMP-SP, 9 (1), 1-29. https://es.mpsp.mp.br/revista_esmp/index.php/RJESMPSP/article/view/295

Minayo, C. S. M., \& Coimbra Jr., C. E. A. (2020). Antropologia, saúde e envelhecimento. Fiocruz. https://static.scielo.org/scielobooks/d2frp/pdf/minayo9788575413043.pdf

Organização Pan-Americana da Saúde. (2021). Folha Informativa COVID-19. https://www.paho.org/pt/covid19

Holliday, O. J. (2006). Para sistematizar experiências. Brasília: Ministério do Meio Ambiente. http://www.edpopsus.epsjv.fiocruz.br/sites/default/files/oscarjara-para-sistematizar-experic3aancias1.pdf

Rodriguez-Morales, A. J. et al. (2020). COVID-19 in Latin America: The implications of the first confirmed case in Brazil. Travel Medicine and Infectious Disease, 35(101613), 1-3. https://doi.org/10.1016/j.tmaid.2020.101613.

Sociedade Brasileira de Geriatria e Gerontologia. (2020). Recomendações para Prevenção e Controle de infecções por coronavírus (SARS-Cov-2) em Instituições de Longa Permanência para Idosos (ILPIs) - Comissão Especial COVID-19. https://sbgg.org.br/recomendacoes-para-prevencao-e-controle-deinfeccoes-por-coronavirus-sars-cov-2-em-instituicoes-de-longa-permanencia-para-idosos-ilpis/

Vieira, L. M. F., Emery, E., \& Andriolo, A. (2020). COVID-19 - Diagnóstico laboratorial para os clínicos São Paulo. Revista Brasileira de Análises Clinicas, 53(2), 1-19. https://doi.org/10.1590/SciELOPreprints.411

World Health Organization. (2020). Infection Prevention and Control Guidance for Long-Term Care Facilities in the Context of COVID-19: interim guidance, 21 March 2020. https://apps.who.int/iris/handle/10665/331508

Zhu, N. et al. (2020). A Novel Coronavirus from Patients with Pneumonia in China. N Engl J Med, 382(8), 727-733. https://doi.org/ 10.1056/NEJMoa2001017. 